\title{
Determination of Overall Equipment Effectiveness Superflex Machine Using Fuzzy Approach
}

\author{
Sesar Husen Santosa ${ }^{\mathrm{a}, 1, *}$, Suhendi Irawan ${ }^{\mathrm{b}, 2}$, Ilham $\operatorname{Ardani}^{\mathrm{a}, 3}$ \\ aIndustrial Management Study Progam, IPB University \\ bVan Hall Larenstein University Of Applied Sciences \\ ${ }^{1}$ sesarhusensantosa@apps.ipb.ac.id ${ }^{2}$ Suhendi.irawan@yahoo.co.id ${ }^{3}$ ilhamardani1999@gmail.com \\ *corresponding author : sesarhusensantosa@apps.ipb.ac.id
}

ABSTRACT

Article history:

Received 27 Nov 2019

Revised 22 March 2020

Accepted 14 Oct 2020

Keywords:

Availability,

Performance,

Quality Yield,

OEE,

Membership Function,

Fuzzy
This study aimed to present a Fuzzy logic approach in determining This study aimed to present a Fuzzy logic approach in determining the value of OEE Superflex machine for producing nuggets. The effectiveness value of Superflex machine in producing nugget raw materials was determined by calculating the Availability, Performance and Quality Yield values. Fuzzy approach in determining the value of OEE can be used because this approach is able to describe the value of the effectiveness of thr machines based on the condition of the company's actual capacities. The Fuzzy OEE approach uses the Trapezoidal Membership Association because the maximum value of the membership degree has more than one value in each parameter. The Fuzzy OEE value shows that Superflex machine had an OEE value with bad parameters so that the company has to improve its machine performance.

Copyright (C) 2017 International Journal of Artificial Intelegence Research. All rights reserved.

\section{Introduction}

The effectiveness of the production machine is an important factor in the success of the production. The effectiveness of this machine configures its ability to utilize the production time in producing products that match their quality and quantity.

In maintaining the effectiveness of the production machine, the company must carry out planned machine maintenance. This activity must be conducted for all machines so that they can work optimally in production activities. Companies engaged in processed food are inseparable from the use of production machines that work continuously as most of them utilize the product layout type.

The nugget processed food company is an example that applies the product layout production type to conduct its production activities. This production type has a characteristic in which the production process runs continuously. This continuous production process requires optimal production machine condition because if one machine breaks down, the entire production line will stop operating.

Production machines can running optimally need periodical evaluation of their condition; one of which is by looking at their effectiveness. The existing instrument to measure the effectiveness of production machines is the Overall Equipment Effectiveness (OEE) value. OEE is a measuring tool that can be used to evaluate the achievement of production target time in producing quality products following the planned operating time of the company [1]. This OEE value can configure the effectiveness of production machines based on the value of the capacity of the machines to use the time to operate (Availability), to use the time for production (Performance), and to produce products that comply with quality standards (Quality Yield). These three variables are the determining factors in calculating the effectiveness of production machines. 
The weakness of OEE calculation is that it only examines the machine condition in producing products and excludes other influential factors; e.g. the company's capacity to provide resources for production. Fuzzy logic can be used in determining the effectiveness of machines because it can build a model based on variables affecting their effectiveness so that the calculation results are accurate as there are linguistic variables in this model [2].

Several factors affect machine productivity in achieving production targets, including the ability of operators, raw materials, the ability of machines to operate, and production scheduling [3]. OEE is a tool that can be used to evaluate the performance of a machine based on the availability of machine operating time (Availability), machine performance to utilize the time for production (Performance), and quality of products produced (Quality Yield) [4].

Based on the best experience in the company, the best value of availability $>90 \%$, performance $>95 \%$, rate of quality product $>99 \%$ and OEE $>85 \%$ [5]. Based on The issue of OEE calculation in this company is that the company considers that OEE's adequate standard value, which according to Seiichi Nakajima is $85 \%$, cannot be achieved as it is exceptionally high. The company currently has OEE value standards based on the profits which it has earned. In this company, the OEE value above $60 \%$ is already highly profitable so that this condition is considered to be adequate. The company cannot reach the OEE value of $85 \%$ because it is limited by current market availability and raw materials.

OEE calculation needs to be performed by looking at the effects of all parameters following the company's condition so that the OEE value of $85 \%$ does not become an absolute provision in determining the effectiveness value of a good production machine. OEE value is affected by Availability, Performance, and Quality Yield. Downtime is a major causative factor in the machine operation for production causing the actual capacity of the machine matches with the resulting production targets [6]

Downtime is divided into 2 types namely planned downtime and unplanned downtime. Planned downtime is set up / adjustment and unplanned downtime is the condition of the machine off out of maintenance schedule [7]. Set up/adjustment is planned downtime in line with the maintenance schedule and can be managed by the company. When the production target is not achieved, it is caused by unnatural downtime as the machine breaks down outside the planned maintenance schedule. Hence, the company may suffer from losses because the machine availability decreases and the production target cannot be achieved [8]. The effectiveness of the production machine can be seen from the machine performance. The decrease in machine performance can be caused by its speed loss causing the production target not to be achieved [9]. One factor affecting the machine OEE value is the number of defective products produced since the machine is not working properly [10].

Fuzzy value determination is done by combining real data and opinions from experts so that they can describe the actual conditions [11]. All influential variables in the calculation process can be included in the fuzzy mathematical model and can be defined as fuzzy numbers so that the model issued is following the conditions of the variables that influence it. In production planning, a parameter that can be measured by a fuzzy approach is production machine capacity [12].

Fuzzy logic can be used to solve complex production problems where several variables influence them; therefore, decision making becomes more accurate [13]. Overall Equipment Effectiveness describes the machine's ability to produce quality products by utilizing available machine operating time [14]. Data used in determining OEE values are downtime, machine operating time, effective time, actual production and product reject [15]. CBM development strategies in the form of Fuzzy Early Warning System (FEWS) is combine fuzzy logic with OEE values to help decision making where the membership set used is the Trapezoidal membership function [16]

Based on the above problems, the Fuzzy OEE calculation is carried out to determine the effective value of the Superflex machine as a critical machine in the nugget production process because the effectiveness of this machine can determine the success of nugget production. 


\section{Reseach Method}

This study aimed to determine the effective value of the Superflex machine in producing nuggets by using Fuzzy approach or called as Fuzzy OEE. The fuzzy approach in determining the OEE value of the Superflex production machine considers the company's ability in the forms of good and bad parameter values.

The fuzzy membership association uses the Trapezoidal type because the Availability, Performance and Quality Yield variables already have standards according to Seiichi Nakajima. Based on these standards, the membership association for all variables uses the trapezoidal type as the peak point of membership degree of all variables has more than one value in each parameter. Based on this condition, the research method can be determined as follows.

\section{Availability}

Availability is the machine capacity to operate or run affected by downtime [17], and it is a condition of the machine in utilizing time to operate. The formulation of Availability is as follows:

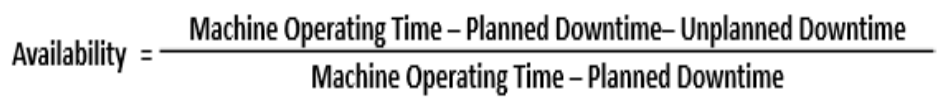

\section{Performance}

Performance is the machine capacity to utilize time for production. Production machine performance is greatly influenced by downtime such as idling and speed lose which can reduce engine performance [18].

Performance value is affected by the production level produced and the effective time achieved by the machine for production [17]. The formulation of Performance is as follows.

$$
\text { Quality Yield }=\frac{\text { Total Actual Production }- \text { Defect Product }}{\text { Total Actual Production }}
$$

\section{Quality Yield}

Quality Yield is the machine capacity to produce products that are not defective or following the quality of the company [17]. The formulation of Quality Yield Value is as follows.

$$
\text { Performance }=\frac{\text { Total Actual Production x Ideal Cycle Time }}{\text { Machine Operating Time }- \text { Planned Downtime- Unplanned Downtime }}
$$

Fuzzy Membership Function

Determination of the Fuzzy Membership Function Model can use the Trapezoid Membership Function of Membership Association [19]. This Function can be used if there are several degrees of membership value of 1 in each parameter. The Trapezoidal fuzzy number of membership Function is in values of $R$ and $a, b 1, b 2, c, x \in R,(a b b 1, b 2 b$ c), and then the membership function $\mu F: R \rightarrow[0,1]$ used is:

$$
\mu_{F}(x)= \begin{cases}(x-a) /\left(b_{1}-a\right), & a \leq x \leq b_{1} \\ 1, & b_{1} \leq x \leq b_{2} \\ (c-x) /\left(c-b_{2}\right), & b_{2} \leq x \leq c \\ 0, & \text { otherwise }\end{cases}
$$

The Trapezoidal membership association is used to determine the OEE value based on the membership degree of Superflex machine's Availability, Performance and Quality Yield parameters.

\section{Fuzzy Relations}

The degree of Fuzzy membership is the y-axis in the Cartesian diagram with a characteristic value of $[0,1]$. The value of each variable is the $x$-axis in which the fuzzy relationship $U=\{x\}$ to $V=\{y\}$ in the 
Cartesian diagram is $\mathrm{U} \times \mathrm{V}$. The differences in the characteristics of the function graph $(\mathrm{x}, \mathrm{y})$ of Trapezoidal membership are as follows: [19]

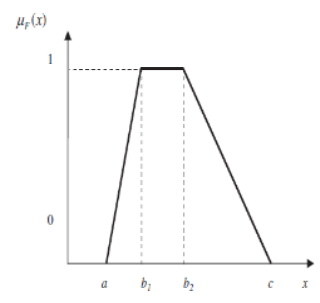

Fig. 1. Trapezoidal fuzzy number.

The logical thinking system is used in developing the Fuzzy Membership Model by using linguistic variables [20]. Determination of OEE values using the Fuzzy approach adopts IF Then Else principle to see the possible parameters chosen for Defuzzification. There are several uses of the Fuzzy Rule Based System including [21]: Being able to determine the number of fuzzy rules that might occur in each variable by using the If Then Else principle. The parameter value obtained in each Membership Association will be changed to the value of membership degree for further defuzzification process. The logical rule simulation is performed on the Fuzzy logic concept in decision making. If the selected operator in Fuzzy Rule Based is "And", the operator is in the minimum value (min); and if the selected operator is "Or", the operator is in the maximum value (max) [22]. Defuzzification is a tool which is used to determine fuzzy values based on the area and moment formed from the Membership Association. The Center of Area (COA) method can be used in determining defuzzification value. COA value is a membership association occurred based on the area obtained from the decision making unit process. The result of defuzzification is OEE value of the Superflex machine. The formulation of COA method to determine OEE is as follows:[23].

$$
x_{C O A}=\frac{\sum_{i=1}^{n} x_{i} \cdot \mu_{i}\left(x_{i}\right)}{\sum_{i=1}^{n} \mu_{i}\left(x_{i}\right)},
$$

\section{Results And Discussions}

Determination of the Superflex machine OEE value was determined based on the Availability, Performance, and Quality Yield values. The results of the three variables were defuzzificated to obtain the OEE value of the Superflex machine. The parameters obtained configured the conditions of the nugget company. Determination of parameter values was carried out by conducting interviews and direct observations related to the nugget production in the Company. The company has conducted an OEE assessment using the Seiichi Nakajima method, but the limit of both parameter values is very high and cannot be achieved by the company because it is related to the availability of raw materials for chicken meat. Besides the company has more than one value for each OEE variable parameter. Comparison of OEE calculation variables with company variable conditions are as follows:

Table 1. Comparison of OEE Calculation Variable

\begin{tabular}{ccccc}
\hline \multirow{2}{*}{ Variable } & \multicolumn{2}{c}{ Seiichi Nakajima's } & Standard & \multicolumn{2}{c}{ Actual Condition of the Company } \\
\cline { 2 - 5 } & Value & Parameter & Value & Parameter \\
\hline \multirow{2}{*}{ 1. Availability } & $>90 \%$ & Good & $0 \%-70 \%$ & Low \\
& $\leq 90 \%$ & $\mathrm{Bad}$ & $70 \%-100 \%$ & Good \\
\cline { 2 - 5 } 2. Performance & $>95 \%$ & Good & $0 \%-70 \%$ & Low \\
& $\leq 95 \%$ & $\mathrm{Bad}$ & $70 \%-100 \%$ & Good \\
\cline { 2 - 5 } 3. Quality Yield & $>99 \%$ & Good & $0 \%-70 \%$ & Low \\
& $\leq 99 \%$ & $\mathrm{Bad}$ & $70 \%-100 \%$ & Good \\
\hline
\end{tabular}




\begin{tabular}{|c|c|c|c|c|}
\hline \multirow{2}{*}{ Variable } & \multicolumn{2}{|c|}{ Seiichi Nakajima's Standard } & \multicolumn{2}{|c|}{ Actual Condition of the Company } \\
\hline & Value & Parameter & Value & Parameter \\
\hline \multirow{2}{*}{ 4. OEE } & $>85 \%$ & Good & $0 \%-60 \%$ & Low \\
\hline & $\leq 85 \%$ & Bad & $60 \%-100 \%$ & Good \\
\hline
\end{tabular}

Based on the company's actual condition, the availability, performance and quality yield variables have more than one parameter value. This condition can show that the determination of OEE values based on the three variables above has a gray area for each parameter so that it can use a fuzzy logic approach to calculate OEE values.

All of these variables were included in the fuzzy set model as variables that affected the Fuzzy OEE model development. The data used for calculation included ideal production, actual production, machine operating time, planned downtime (set up adjustment), unplanned downtime and total defective products. The data used included the Superflex machine productions for one year, in 2018 . The data used in the calculation process of Availability, Performance, and Quality Yield of Superflex machine are as follows:

Table 2. Calculation Data of Superflex Machine OEE in 2018

\begin{tabular}{|c|c|c|c|c|c|c|c|c|c|c|c|}
\hline \multirow[b]{2}{*}{ Month } & \multirow[b]{2}{*}{$\begin{array}{l}\text { Actual } \\
\text { Production } \\
\text { (Kg) }\end{array}$} & \multirow[b]{2}{*}{$\begin{array}{c}\text { Ideal } \\
\text { Production } \\
\text { (Kg) }\end{array}$} & \multirow[b]{2}{*}{$\begin{array}{c}\text { Machine } \\
\text { Operating Time } \\
\text { (Hour) }\end{array}$} & \multicolumn{4}{|c|}{ Planned Downtime } & \multicolumn{3}{|c|}{ Unplanned Downtime } & \multirow[b]{2}{*}{$\begin{array}{l}\text { Operating Load } \\
\text { Time (Hour/Kg) }\end{array}$} \\
\hline & & & & $\begin{array}{l}\text { Set Up } \\
\text { (Hour) }\end{array}$ & $\begin{array}{c}\begin{array}{c}\text { No order time } \\
\text { (Hour) }\end{array} \\
\end{array}$ & $\begin{array}{l}\text { Others } \\
\text { (Hour) }\end{array}$ & $\begin{array}{c}\text { Total } \\
\text { (Hour) }\end{array}$ & $\begin{array}{c}\text { Production } \\
\text { Downtime } \\
\text { (Hour) }\end{array}$ & $\begin{array}{c}\text { Machine } \\
\text { Downtime } \\
\text { (Hour) }\end{array}$ & $\begin{array}{c}\text { Total } \\
\text { (Hour) }\end{array}$ & \\
\hline January & 45402,30 & 229861,33 & 696,00 & 71,82 & 49,53 & 0,00 & 121,35 & 3,08 & 4,58 & 7,67 & 574,65 \\
\hline February & 64806,70 & 193234,67 & 552,00 & 36,08 & 32,83 & 0,00 & 68,91 & 3,33 & 8,00 & 11,33 & 483,09 \\
\hline March & 63877,30 & 136505,33 & 528,00 & 54,82 & 131,92 & 0,00 & 186,74 & 5,58 & 6,75 & 12,33 & 341,26 \\
\hline April & 71239,77 & 146268,00 & 552,00 & 50,00 & 136,33 & 0,00 & 186,33 & 2,92 & 3,00 & 5,92 & 365,67 \\
\hline May & 103864,00 & 217393,33 & 624,00 & 80,52 & 0,00 & 0,00 & 80,52 & 4,00 & 7,17 & 11,17 & 543,48 \\
\hline June & 64326,10 & 136760,00 & 432,00 & 37,10 & 53,00 & 0,00 & 90,10 & 2,33 & 6,08 & 8,42 & 341,90 \\
\hline July & 105946,50 & 172246,67 & 576,00 & 57,38 & 88,00 & 0,00 & 145,38 & 3,08 & 17,58 & 20,67 & 430,62 \\
\hline Agust & 99831,38 & 215234,67 & 672,00 & 67,33 & 66,58 & 0,00 & 133,91 & 0,00 & 21,75 & 21,75 & 538,09 \\
\hline September & 55304,31 & 66300,00 & 552,00 & 26,17 & 354,67 & 5,42 & 386,25 & 1,25 & 4,67 & 5,92 & 165,75 \\
\hline October & 46121,25 & 148566,67 & 720,00 & 39,52 & 300,67 & 8,40 & 348,58 & 0,00 & 2,50 & 2,50 & 371,42 \\
\hline November & 82969,66 & 103400,00 & 552,00 & 116,33 & 152,67 & 24,50 & 293,50 & 0,00 & 5,67 & 5,67 & 258,50 \\
\hline December & 95135,50 & 103478,67 & 576,00 & 33,42 & 265,42 & 18,47 & 317,30 & 0,00 & 2,83 & 2,83 & 258,70 \\
\hline
\end{tabular}

Based on the data, the values of Availability, Performance and Quality Yield were determined. The three variables affected the process of determining the OEE values and can be explained as follows. Determination of Availability value is affected by several factors including Machine Operation Time, Planned Downtime, and Unplanned Downtime. The data used included the Superflex machine activities for one year of 2018. The calculation data of Superflex machine availability are as follows.

Table 3. Results of Superflex Machine Availability

\begin{tabular}{cccc}
\hline Month & Operational Load Time (Hour) & $\begin{array}{c}\text { Effective Time } \\
\text { (Hour) }\end{array}$ & Performance \\
\hline January & 574.65 & 566.99 & $98.67 \%$ \\
February & 483.09 & 471.75 & $97.65 \%$ \\
March & 341.26 & 328.93 & $96.39 \%$ \\
April & 365.67 & 359.75 & $98.38 \%$ \\
May & 543.48 & 532.32 & $97.95 \%$ \\
June & 341.90 & 333.48 & $97.54 \%$ \\
July & 430.62 & 409.95 & $95.20 \%$ \\
August & 538.09 & 516.34 & $95.96 \%$ \\
September & 165.75 & 159.83 & $96.43 \%$ \\
October & 371.42 & 368.92 & $99.33 \%$ \\
November & 258.50 & 252.83 & $97.81 \%$ \\
December & 258.70 & 255.86 & $98.90 \%$ \\
\hline
\end{tabular}


Based on the calculation results of Superflex machine, the availability value of 2018 was $97.52 \%$. This value shows that the utilization of Superflex machine operating time was only $97.52 \%$ of the machine operating time provided by the company. This value shows a good indicator because according to Seiichi Nakajima, the standard of good Availability value is above $90 \%$. This condition is caused by the company's well-scheduled maintenance, so that unplanned downtime can be managed well. Up to now, the company has had no problems in the machine availability value as the machines can operate in accordance with the expected operating time targets. The calculation of machine performance needs to be carried out to examine whether the machine is running in production condition or not.

Determination of the Superflex machine performance value is affected by the number of ideal production, actual production, and effective time of the production machines. The data used included the Superflex machine activities for one year of 2018. Based on the Superflex machine activity data, the calculation results obtained in 2018 are as follows.

Table 4. Results of Superflex Machine Performance

\begin{tabular}{cccc}
\hline Month & $\begin{array}{c}\text { Ideal Cycle Time } \\
(\mathrm{Jam} / \mathrm{Kg})\end{array}$ & $\begin{array}{c}\text { Actual Cycle Time } \\
(\mathrm{Jam} / \mathrm{Kg})\end{array}$ & Performance \\
\hline January & 0.0025 & 0.0125 & $20.02 \%$ \\
February & 0.0025 & 0.0073 & $34.34 \%$ \\
March & 0.0025 & 0.0051 & $48.55 \%$ \\
April & 0.0025 & 0.0050 & $49.51 \%$ \\
May & 0.0025 & 0.0051 & $48.78 \%$ \\
June & 0.0025 & 0.0052 & $48.22 \%$ \\
July & 0.0025 & 0.0039 & $64.61 \%$ \\
August & 0.0025 & 0.0052 & $48.34 \%$ \\
September & 0.0025 & 0.0029 & $86.50 \%$ \\
October & 0.0025 & 0.0080 & $31.25 \%$ \\
November & 0.0025 & 0.0030 & $82.04 \%$ \\
December & 0.0025 & 0.0027 & $92.96 \%$ \\
\hline
\end{tabular}

Bassed on the results of the Superflex machine calculation, the value of machine performance in 2018 was $54.59 \%$ showing that the use of time for production was only $54.59 \%$ of the effective time of production machine. This value shows that the Superflex machine Performance is in bad condition because according to Seiichi Nakajima, the good Performance value should be above $95 \%$. Poor machine performance is due to production quantities that are far below the company's ideal production conditions as the number of product demands does not match the production targets. Quality Yield is a calculation parameter used to examine the ability of Superflex machine to produce products in appropriate quality. The data used in the calculation of Quality Yield are the the actual amount of production and the number of defect products for one year of 2018

Table 5. Calculation Data of Quality Yield

\begin{tabular}{ccc}
\hline Month & Actual Production $(\mathrm{Kg})$ & Defective Product $(\mathrm{Kg})$ \\
\hline January & 45402.30 & 0 \\
February & 64806.70 & 0 \\
March & 63877.30 & 0 \\
April & 71239.77 & 0 \\
May & 103864.00 & 0 \\
June & 64326.10 & 0 \\
July & 105946.50 & 0 \\
August & 99831.38 & 0 \\
September & 55304.31 & 0
\end{tabular}




\begin{tabular}{ccc}
\hline Month & Actual Production $(\mathrm{Kg})$ & Defective Product $(\mathrm{Kg})$ \\
\hline October & 46121.25 & 0 \\
November & 82969.66 & 0 \\
December & 95135.50 & 0 \\
\hline
\end{tabular}

Based on the production results of the Superflex machine, it is found that there was no defective product in 2018. This condition shows that the Quality Yield value of this machine was $100 \%$. This condition can be achieved by the company for the past one year because the company has implemented a production system integrated with a good machine maintenance process.

Fuzzy set model in determining the OEE value needs to be conducted by this company because each variable affecting OEE has a parameter value that must be adjusted to the company's condition. The standard used in determining the Availability, Performance and Quality Yield values is still Seiichi Nakajima's standard in which it uses a fixed set of principles. The calculation of OEE values using the Fuzzy approach is that each variable (availability, performance, and quality yield) is given parameters that configure the company's capacity.

The real condition that occurs in the company is that the company has obtained profits when the OEE value reaches $60 \%$; therefore, according to the company, the parameter in this value is included in the good category. However, referring to Seiichi Nakajima's standards, this value is considered low as it is below $85 \%$. Based on these conditions, the calculation of OEE Superflex machine uses the Trapezoidal Membership Association for the Availability, Performance and Quality Yield variables.

The Superflex machine Availability value of membership association was determined using Trapezoidal Membership Association. This Membership Association had 2 parameters: High and Low. Both variables configured the company's actual conditions in achieving Availability. The Superflex machine availability parameters can be seen in the following table.

Table 6. Availability Parameter

\begin{tabular}{cc}
\hline Parameter & Parameter Value (\%) \\
\hline High & 7090100100 \\
Low & 005070 \\
\hline
\end{tabular}

Based on the parameter value of the Superflex Machine Availability Membership Association, the membership association is $\mu_{\mathrm{x}}(\mathrm{a}, \mathrm{b} 1, \mathrm{~b} 2, \mathrm{c}$ ) for each parameter held. The model of Superflex machine membership association based on the above parameters is as follows:

$$
\text { Fx(a,b1,b2,c) }\left\{\begin{array}{cl}
0 & x \leq 0 \\
1 & 0 \leq x \leq 50 \% \\
\frac{70 \%-x}{20 \%} & 50 \% \leq x \leq 70 \% \\
\frac{x-70 \%}{20 \%} & 70 \% \leq x \leq 90 \% \\
1 & 90 \% \leq x \leq 100 \%
\end{array}\right.
$$

Based on the parameters owned, the graph of Membership Association can be configured based on the Availability Superflex machine value of 0.972 (97.2\%). The graph of membership association for the Superflex machine availability is as follows: 


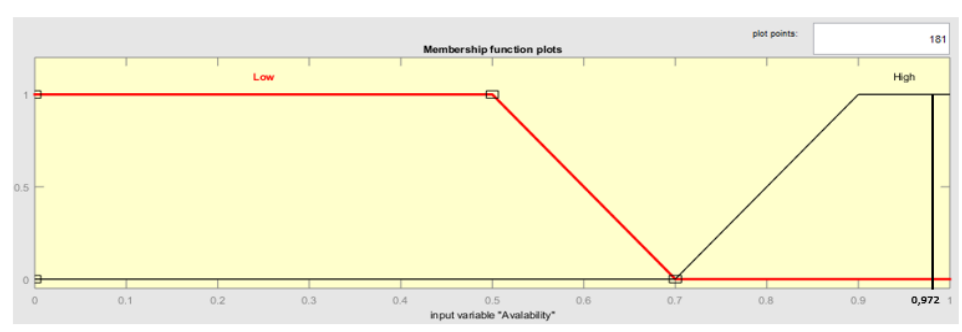

Fig. 2. Graph of Availability Membership Association

Based on the membership association graph, it can be seen that the Availability value of 0.972 $(97.2 \%)$ is in the highest parameter. Based on this parameter, the value of membership degree for the Superflex machine Availability is 1.

The Superflex Machine Performance variable of Membership Association was determined using the Trapezoidal Membership Association. This membership association had 2 parameters: High and Low. Both parameters configured the company's actual conditions towards achieving machine performance. The Superflex machine performance parameters can be seen in the following table

Table 7. Performance Parameter

\begin{tabular}{cc}
\hline Parameter & Parameter Value $(\%)$ \\
\hline High & 7095100100 \\
Low & 004070 \\
\hline
\end{tabular}

The value parameter of Superflex Machine Performance Membership Association was $\mu_{\mathrm{x}}$ (a, b1, b2, c) for each parameter held. The model of Superflex Machine Performance Membership Association based on the parameters is as follows.

$$
F \times(a, b 1, b 2, c)\left\{\begin{array}{cl}
0 & x \leq 0 \\
1 & 0 \leq x \leq 0,4 \\
\frac{0,7-x}{0,3} & 0,4 \leq x \leq 0,7 \\
\frac{x-0,7}{0,25} & 0,7 \leq x \leq 0,95 \\
1 & 0,95 \leq x \leq 1
\end{array}\right.
$$

Based on the parameters owned, the graph of Membership Association can be configured based on the Superflex machine Performance value of 0.546 (54.6\%). The graph of Superflex Machine Performance Membership Association based on the machine's Performance value is as follows

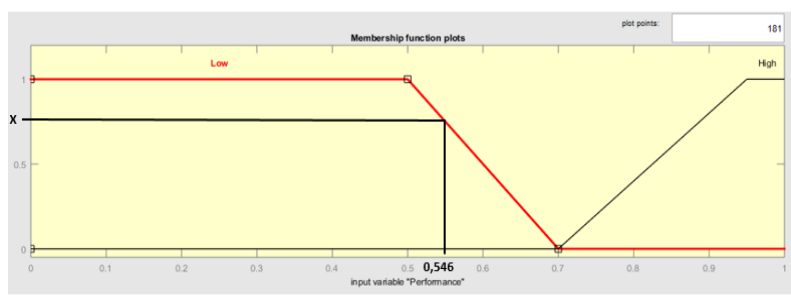

Fig. 3.Graph of Performance Membership Association

Based on the graph of Machine Performance Membership Association, the value of Performance membership degree 0.546 (54.6\%) was 0.536 with the calculation as follows:

$$
\begin{array}{r}
0,546=\frac{0,7-x}{3} \\
x=0,536
\end{array}
$$


Membership association of Superflex machine Quality Yield value was determined using the Trapezoidal Membership Association. This membership association had 2 parameters: High and Low. Both variables configured the company's actual condition in achieving the quality of the product produced. The Superflex machine Yield Quality parameters can be seen in the following table:

Table 8. Quality Yield Parameter

\begin{tabular}{cc}
\hline Parameter & Parameter Value (\%) \\
\hline High & 9099100100 \\
Low & 007090 \\
\hline
\end{tabular}

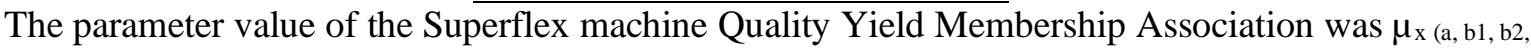
c) for each parameter held. The model of Superflex machine Quality Yield Membership Association based on the above parameters is as follows:

$$
\mathrm{F} \times(a, b 1, b 2, c)\left\{\begin{array}{cl}
0 & x \leq 0 \\
1 & 0 \leq x \leq 0,7 \\
-\frac{0,9-x}{0,2} & 0,7 \leq x \leq 0,9 \\
\frac{x-0,9}{0,09} & 0,9 \leq x \leq 0,99 \\
1 & 0,99 \leq x \leq 1
\end{array}\right.
$$

Based on the parameters, the graph of Membership Association can be configured based on the Superflex machine Quality Yield value of $1(100 \%)$. The graph of Superflex machine Quality Yield Membership Association based on the Superflex machine Quality Yield value is as follows.

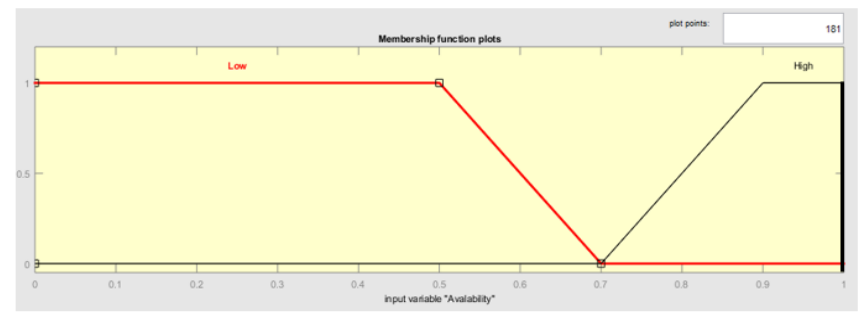

Fig. 4.Graph of Quality Yield Membership Association

Based on the Membership Association Graph, the Quality Yield Value of 1 was found in High parameter and had a membership degree value of 1. Membership association of Superflex machine OEE value was determined using the Trapezoidal membership association. This membership association had 2 parameters: i.e. High and Low. Both variables configured the company's actual condition towards the OEE achievement. The OEE parameters of the Superflex machine can be seen in the following Table.

Table 9. OEE Parameters

\begin{tabular}{cc}
\hline Parameter & Parameter Value $(\%)$ \\
\hline High & 6085100100 \\
Low & 003060 \\
\hline
\end{tabular}

The parameter value of the Superflex machine OEE Membership Association is for each parameter held. The model of Superflex machine OEE Membership Association based on the above parameters is as follows: 


$$
\operatorname{Fx}(a, b 1, b 2, c)\left\{\begin{array}{cl}
0 & x \leq 0 \\
1 & 0 \leq x \leq 0,3 \\
\frac{0,6-x}{0,3} & 0 \leq x \leq 0,6 \\
\frac{x-0,6}{0,25} & 0,6 \leq x \leq 0,85 \\
1 & 0,85 \leq x \leq 1
\end{array}\right.
$$

This OEE Membership Association will be used to determine the effectiveness value of the Superflex production machine using the Fuzzy Logic approach. The next step was to determine the possibilities that will occur in each parameter. This process used the Fuzzy Rule Base System. Fuzzy Rule Base System in Fuzzy approach functions to examine the possibilities that might occur from each parameter. The principle in Fuzzy Rule Base is to use IF Than Else principle. In determining the OEE value of Superflex machine, the Availability, Performance, and Quality Yield variables had 2 parameters: "High" and "Low". Based on these two parameters, 16 possible parameters that might occur were obtained. Possibilities for each parameter can be seen in the following Figure:

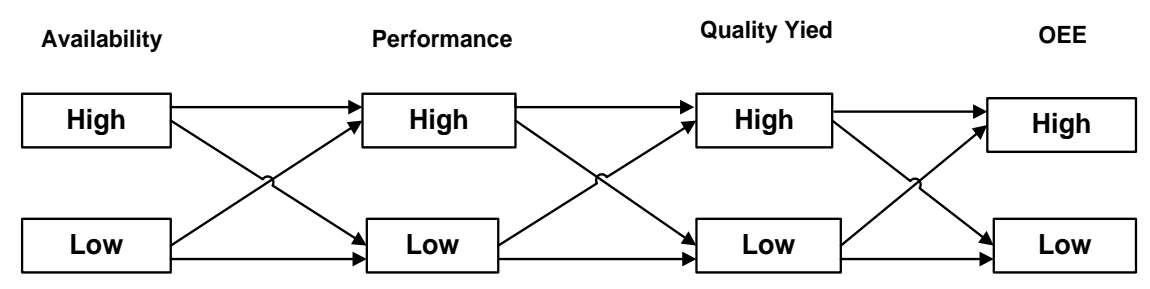

Fig. 5.Fuzzy Rule Based OEE

Decission Making Unit digunakan untuk Decision Making Unit is used to determine the value of selected Fuzzy Rule Based using operators in accordance with the conditions in determining the OEE Superflex Machine value. The operator used in the Decision Making Unit is "And" in which the selected value from the combination of IF Then Else is "Min".

Based on the determination of Membership Association, the Superflex machine parameters obtained include high availability, low performance, and high quality yield. Based on these conditions, the Decision Making Unit obtained is as follows:

$$
\begin{aligned}
\alpha & =\operatorname{Min}\left(\mu_{\text {Tinggi }[1]} \cap \mu_{\text {Rendah }[0,536]} \cap \mu_{- \text {Tinggi }[1]}\right) \\
& =\operatorname{Min}(1 ; 0,536 ; 1) \\
\alpha & =\mathbf{0 , 5 3 6}
\end{aligned}
$$

Based on the value of the Decision Making Unit, the area and moment of OEE value can be determined. OEE Membership Association Graph with a value of $\boldsymbol{\alpha}=\mathbf{0 . 5 3 6}$ can be seen in the following Figure:

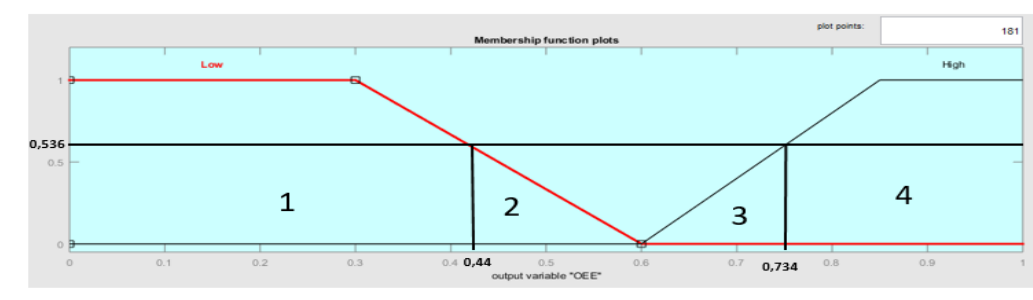

Fig. 6. Graph of OEE Membership Association 
Based on the Membership Association Graph, the OEE Membership Association obtained based on $\boldsymbol{\alpha}=\mathbf{0 . 5 3 6}$ is as follows:

$$
\operatorname{Fx}(\mathrm{a}, \mathrm{b} 1, \mathrm{~b} 2, \mathrm{c})\left\{\begin{array}{cc}
0 & \mathrm{x} \leq \mathrm{0} \\
\frac{0,536}{0,6-\mathrm{x}} & 0 \leq \mathrm{x} \leq 0,44 \\
\frac{0,3}{\mathrm{x}-0,6} & 0,44 \leq \mathrm{x} \leq 0,6 \\
0,25 & 0,6 \leq \mathrm{x} \leq 0,734 \\
0,536 & 0,734 \leq \mathrm{x} \leq 1
\end{array}\right.
$$

Defuzzification process consists of 3 parts: the determinations of Areas, Moments, and calculation using the Center of Area (COA). Based on the OEE Membership Association, there are 4 regions that must be calculated before the defuzzification process is carried out. The followings are the Areas of the OEE Membership Association:

$$
\begin{aligned}
\text { LD 1 } & =(0,44-0) \times 0,536=0,235 \\
\text { LD 2 } & =\frac{(0,6-0,44) \times 0,536}{2}=0,043 \\
\text { LD 3 } & =\frac{(0,734-0,6)}{2}=0,036 \\
\text { LD 4 } & =0,14
\end{aligned}
$$

Based on the results of area determination of the Superflex OEE Membership Association, the total OEE Area was 0.457. Subsequently, the process of determining moments of each area occurred in OEE Membership Association was conducted Determination of Moments is based on the Areas of the Superflex Machine Membership Association. The moments obtained from the Graph of Superflex machine OEE Membership Association are as follows.

$$
\begin{aligned}
& \text { Moment } 1=\int_{0}^{0.44} 0.536 x d x=0.053 \\
& \text { Moment } 2=\int_{0.44}^{0.6} 2 x-3.33 x 2 d x=0.21 \\
& \text { Moment } 3=\int_{0.6}^{0.724} 4 x 2-2.4 x d x=0.022 \\
& \text { Moment } 4=\int_{0.794}^{1} 0.536 x d x
\end{aligned}
$$

Based on the determination of Moments, the total Moments occurred in Superflex Machine OEE Membership Association can be revealed. The total moments obtained were 0.218. This model was developed using Matlab software R2015a series. This model can be used as a tool for companies to evaluate the effectiveness value of Superflex machine so that the company can conduct continuous improvement activities on the machine. The Fuzzy model of OEE Superflex machine developed in Matlab software R2015a series can be seen in the following figure: 


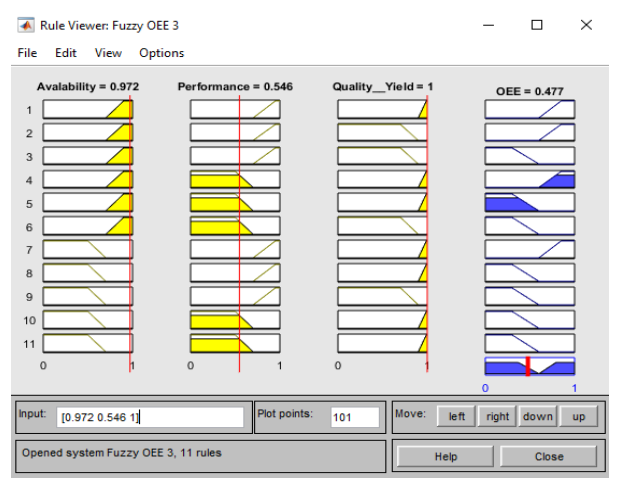

Fig. 7.Fuzzy Model of OEE Superflex Machine

The OEE value determination of Superflex machine used Fuzzy approach in which the defuzzification method used was Center of Area (COA). Based on this method, the OEE value obtained from the Superflex machine using the Fuzzy approach was 0.477 (47.7\%). The OEE value determination model through the Fuzzy approach can be used by companies to evaluate the effectiveness of the machine as this method is based on the actual condition of the company's capacities.

\section{Conclusion}

Determination of OEE values using the Fuzzy approach was conducted by looking at the condition of the company's capacities. This condition affects the determination of parameters of Availability, Performance and Quality Yield values of the Superflex machine. OEE values can be used as a monitoring and evaluation tool for the effectiveness of the Superflex machine. The results of the OEE value using the Fuzzy approach showed a value of $47.7 \%(0.477)$. This condition shows that the effectiveness of the machine is still poor; therefore, the company must make improvements, especially on the Superflex machine performance.

\section{Acknowledgment}

The authors would like to express their gratitude for those who assisted in the preparation of this research, especially the Industrial Management Study Program of the Vocational School of Bogor Agricultural University and PT ABC as the company engaged in nugget processing food industry which provided input, data and information to support the writing of this scientific paper.

\section{References}

[1] S. E. G. Da Costa and E. P. De Lima, "Uses and misuses of the 'overall equipment effectiveness' for production management," IEEE Int. Eng. Manag. Conf., vol. 2, pp. 816820, 2002.

[2] F. Zammori, "Fuzzy Overall Equipment Effectiveness (FOEE): Capturing performance fluctuations through LR Fuzzy numbers," Prod. Plan. Control, vol. 26, no. 6, pp. 451-466, 2015.

[3] R. Oechsner, M. Pfeffer, L. Pfitzner, H. Binder, E. Müller, and T. Vonderstrass, "From overall equipment efficiency (OEE) to overall Fab effectiveness (OFE)," Mater. Sci. Semicond. Process., vol. 5, no. 4-5 SPEC., pp. 333-339, 2002.

[4] R. Singh, D. B. Shah, A. M. Gohil, and M. H. Shah, "Overall equipment effectiveness (OEE) calculation - Automation through hardware \& software development," Procedia Eng., vol. 51, pp. 579-584, 2013.

[5] Nakajima, "Seiichi Nakajima - Introduction to TPM (Total Productive Maintenance) (1988, Productivity Press)." 1988.

[6] R. Wudhikarn, "Improving overall equipment cost loss adding cost of quality," Int. J. Prod. Res., vol. 50, no. 12, pp. 3434-3449, 2012.

[7] I. Zennaro, D. Battini, F. Sgarbossa, A. Persona, and R. De Marchi, "Micro downtime: Data 
collection, analysis and impact on OEE in bottling lines the San Benedetto case study," Int. J. Qual. Reliab. Manag., vol. 35, no. 4, pp. 965-995, 2018.

[8] F. Anvari, R. Edwards, and A. Starr, "Methodology and theory evaluation of overall equipment effectiveness based on market," J. Qual. Maint. Eng., vol. 16, no. 3, pp. 256$270,2010$.

[9] P. H. Tsarouhas, "Evaluation of overall equipment effectiveness in the beverage industry: A case study," Int. J. Prod. Res., vol. 51, no. 2, pp. 515-523, 2013.

[10] P. Muchiri and L. Pintelon, "Performance measurement using overall equipment effectiveness (OEE): Literature review and practical application discussion," Int. J. Prod. Res., vol. 46, no. 13, pp. 3517-3535, 2008.

[11] K. Govindan, A. Diabat, and K. Madan Shankar, "Analyzing the drivers of green manufacturing with fuzzy approach," J. Clean. Prod., vol. 96, pp. 182-193, 2015.

[12] A. Baykasoglu and T. Gocken, "Multi-objective aggregate production planning with fuzzy parameters," Adv. Eng. Softw., vol. 41, no. 9, pp. 1124-1131, 2010.

[13] J. C. Figueroa-García, D. Kalenatic, and C. A. Lopez-Bello, "Multi-period Mixed Production Planning with uncertain demands: Fuzzy and interval fuzzy sets approach," Fuzzy Sets Syst., vol. 206, pp. 21-38, 2012.

[14] C. Andersson and M. Bellgran, "On the complexity of using performance measures: Enhancing sustained production improvement capability by combining OEE and productivity," J. Manuf. Syst., vol. 35, pp. 144-154, 2015.

[15] T. Ylipää, A. Skoogh, J. Bokrantz, and M. Gopalakrishnan, "Identification of maintenance improvement potential using OEE assessment," Int. J. Product. Perform. Manag., vol. 66, no. 1 , pp. 126-143, 2017.

[16] N. Vafaei, R. A. Ribeiro, and L. M. Camarinha-matos, "Title :," Comput. Ind. Eng., 2018.

[17] J. A. Garza-Reyes, S. Eldridge, K. D. Barber, and H. Soriano-Meier, "Overall equipment effectiveness (OEE) and process capability (PC) measures: A relationship analysis," Int. J. Qual. Reliab. Manag., vol. 27, no. 1, pp. 48-62, 2010.

[18] M. baghbani, S. Iranzadeh, and M. Bagherzadeh khajeh, "Investigating the relationship between RPN parameters in fuzzy PFMEA and OEE in a sugar factory," J. Loss Prev. Process Ind., vol. 60, no. May, pp. 221-232, 2019.

[19] J. Rezaei and R. Ortt, "Supplier segmentation using fuzzy logic," Ind. Mark. Manag., vol. 42, no. 4, pp. 507-517, 2013.

[20] Y. A. Phillis and L. A. Andriantiatsaholiniaina, "Sustainability: An ill-defined concept and its assessment using fuzzy logic," Ecol. Econ., vol. 37, no. 3, pp. 435-456, 2001.

[21] J. S. R. Jang, "ANFIS: Adaptive-Network-Based Fuzzy Inference System," IEEE Trans. Syst. Man Cybern., 1993.

[22] E. H. Mamdani, "Advances in the linguistic synthesis of fuzzy controllers," Int. J. Man. Mach. Stud., vol. 8, no. 6, pp. 669-678, 1976.

[23] A. Amindoust, S. Ahmed, A. Saghafinia, and A. Bahreininejad, "Sustainable supplier selection: A ranking model based on fuzzy inference system," Appl. Soft Comput. J., vol. 12, no. 6, pp. 1668-1677, 2012. 